RESEARCH AND PRACTICE

\title{
Gender disparities in weight gain among offenders who are obese upon entering correctional facilities
}

\author{
Madison L. Gates, PhD, Nancy C. Webb, PhD, Rebecca Stone, DrPH, Darra Ballance, MLIS, and Wonsuk Yoo, PhD \\ Institute of Public \& Preventive Health, Augusta University, Augusta, GA
}

\begin{abstract}
Background: Obesity is a significant health issue for offenders, who have a higher prevalence of obesity-related conditions, such as diabetes, compared to non-incarcerated populations. Within incarcerated populations, there are obesity disparities in terms of race, gender, and age, as well as excess weight gain during incarceration.

Methods: This longitudinal study was conducted for 2005 - 2010 in collaboration with a Department of Corrections in the east south central region of the United States. From electronic health records of 10,841 offenders, weight, height, and demographic data were extracted. As determined from these data, 2,622 offenders met the inclusion criteria (two or more valid weight and height measurements and length of incarceration $>$ zero).

Results: Women offenders who entered corrections as obese had a mean (and standard deviation) body mass index (BMI) of 36.2 (5.3) at baseline; the mean for men was 34.2 (4.4). For women who were obese at baseline, their BMI increased by 1.0 (3.3); for men their BMI decreased by 0.7 (3.1). Gender differences for changes in BMI among the obese population were significant $\left(\chi^{2}=15.8, \mathrm{p}<0.001\right)$. Women and men also differed in regard to weight gain $\left(\chi^{2}=34.0, p<0.001\right)$. Further, those women and men who were not obese at baseline had an increase in BMI that was greater than the increase for the group that entered corrections as obese $(p>0.001)$.

Conclusions: Women offenders, obese or not at baseline, had greater gains in weight in comparison to men. However, there were no significant differences in BMI changes for race or correlations with age or length of incarceration. The findings related to gender warrant further investigations to explain these disparities and to evaluate the capacity of the corrections system to meet the health needs of women.
\end{abstract}

Keywords: body mass index, obesity, offenders, women’s health

\section{INTRODUCTION}

Obesity is a significant health issue for offenders, individuals who are either incarcerated in a jail (durations less than a year) or prison (durations greater than a year). Despite the importance of the issue, offenders, a vulnerable and priority population, are not typically included in national health surveys in regard to obesity (Houle, 2011). Several studies that have included offenders indicated that the population typically gains weight during incarceration (Clarke \& Waring, 2012; Gates \& Bradford, 2015; Houle, 2014). The Bureau of Justice Statistics found that $73.6 \%$ of state and federal offenders were either overweight or obese (Maruschak, Berzofsky, \& Unangst, 2015). They also found that offenders, in comparison to the non-incarcerated population, had higher prevalence of obesity-related conditions, such as diabetes, hypertension, and heart problems, and that obesity was more prevalent for African Americans, women, and older offenders relative to Whites, men and younger groups.

The effect of incarceration on weight gain and factors related to offenders becoming overweight and obese continue to emerge from investigations dealing with this population (Clarke \& Waring, 2012; Gates \& Bradford,
2015; Houle, 2011, 2014; Maruschak et al., 2015). The present study investigated a subpopulation of offenders, a group that entered corrections classified as obese. The purpose was to investigate the effect of incarceration on a population that is at greater risk for chronic diseases, such as diabetes, hypertension and heart problems; may have poorer health histories; and is likely in greater need of health services than those who do not enter corrections as obese. The primary goal was to determine changes in body mass index (BMI), changes in weight, and whether or not there was significant weight gain for the population classified as obese at baseline. Also investigated were differences in regard to gender and race.

\section{METHODS}

This longitudinal, retrospective study was approved by an institutional review board (Protocol number: 10-0382F2L) at an academic health center in the east south central region of the United States and was conducted in collaboration with a state Department of Corrections (DOC). The records of a sample of offenders were examined, and the offenders were categorized as being obese or non-obese at baseline, as shown in Figure 1. 


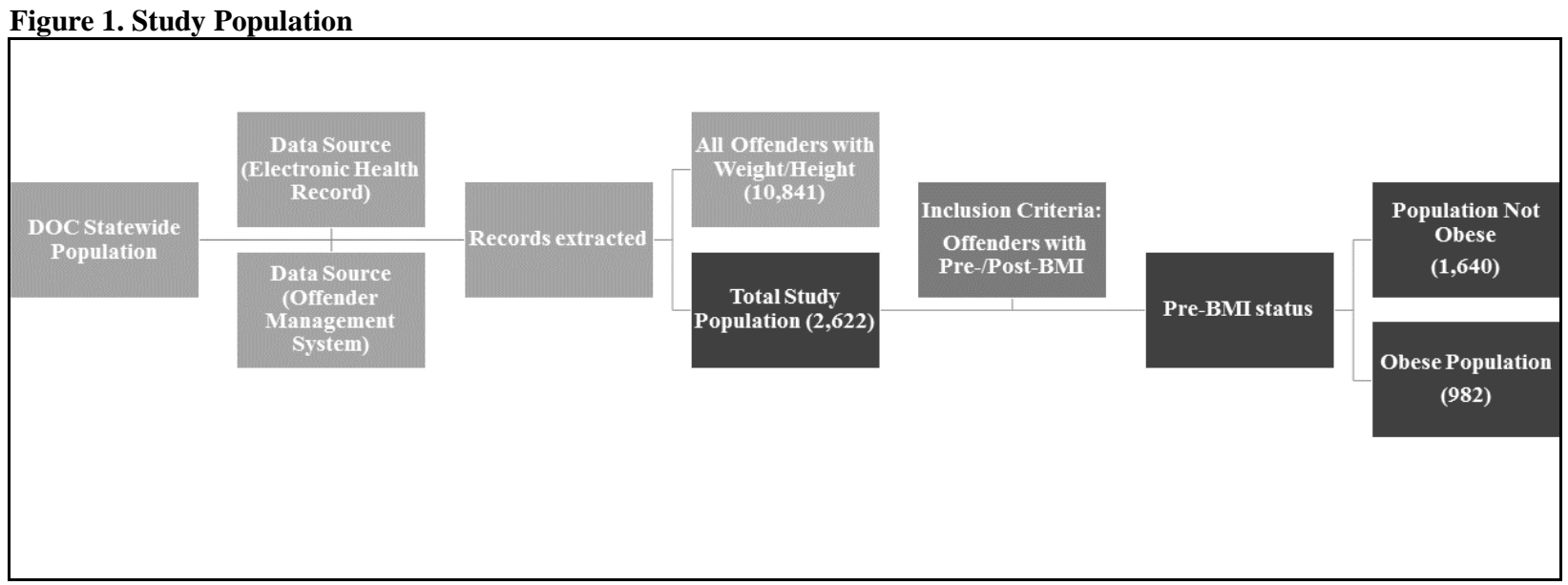

All health data (weight, height, and measurement dates) were extracted from the electronic health records of the DOC. All offenders have an electronic health record, which is created by clinic staff upon their arrival at a reception center of a state correctional facility. At the center, offenders receive a physical and dental examination and mental health screening. Demographic and non-health related data (race, ethnicity, gender, date of birth, and sentence date) were collected from an offender management system, an electronic tracking and case management system created from court records and managed by correctional officers and counselors.

The extraction criteria for the electronic health records and the offender management system were defined as active records between June 1, 2005 and December 31, 2010. However, only records for those who had at least two weight observations, a valid height measurement, and a length of incarceration greater than zero were included. BMI values were derived by use of weight and height (weight in $\mathrm{kg} /$ height in $\mathrm{m}^{2}$ ) and were classified by use of the World Health Organization's (WHO) system (Table 1) (World Health Organization, 2004). Medically significant weight gain was defined as an increase $\geq 7 \%$ of baseline weight, which other investigators have used as a cut-off point (Arterburn et al., 2015; Bak, Fransen, Janssen, van Os, \& Drukker, 2014; Curtis et al., 2015; Tek et al., 2015). Percent weight change was calculated as follows: (post-weight pre-weight) / pre-weight.

Table 1. WHO BMI Classification (World Health Organization, 2004)

Classification Cut-off point

\begin{tabular}{ll} 
Underweight & $<18.5$ \\
Normal weight & $18.5-24.9$ \\
Overweight & $25.0-29.9$ \\
Obesity Class I & $30.0-34.9$ \\
Obesity Class II & $35.0-39.9$ \\
Obesity Class III & $\geq 40.0$ \\
\hline
\end{tabular}

Descriptive analyses were performed to summarize categorical variables, such as race and gender, using frequencies and proportions. Continuous data (e.g., changes in BMI, percent weight change, age, and length of incarceration) were analyzed using means, standard deviations and interquartile ranges. Population proportions and group differences were assessed by chi-square $\left(\chi^{2}\right)$ statistics and Wilcoxon rank-sum test. Since the population was overwhelmingly African American and White (97.6\%), race comparisons were limited to these two groups. All statistical tests were performed with a two-sided significance level of 0.05 , and statistical analyses were performed with SAS ${ }^{\circledR}$ version 9.4 (Statistical Analysis Software Institute, Cary, NC).

\section{RESULTS}

The inclusion criteria of valid weight and height observations resulted in 2,622 offender records, of which $982(37.5 \%)$ had a BMI $\geq 30$ when they entered corrections. The population classified as obese at baseline (i.e., BMI $\geq$ 30 ) was mostly White (60.4\%) and male (87.9\%); however, the percentages of Whites and men who were obese at baseline were less than the percentages of Whites and men in the total population (63.2\% and $93.8 \%$ respectively). Women offenders who were obese at baseline were overrepresented relative to the total population. In the sample, $12.1 \%$ were obese compared to $6.3 \%$ in the total population.

Women in corrections who were obese at baseline (72.6\%) also exceeded the percent of women who are obese in the non-incarcerated population (31.1\%) (BRFSS Prevalence \& Trends Data, 2015). Men who were obese at baseline (35.1\%) exceeded the male distribution in the nonincarcerated population (29.6\%), but by a smaller ratio than women (BRFSS Prevalence \& Trends Data, 2015). African Americans comprised $34.2 \%$ of the total population and $37.2 \%$ of the population who were obese at baseline. Further, the population classified as obese at baseline was older (40.6 compared to 40.2 years) but had been incarcerated for less time (9.7 compared to 10.5 years) than those who were not obese when they entered corrections.

According to the WHO system, the women who were obese at baseline would be classified in Obesity Class II and the men who were obese as Obesity Class I. Changes between pre- and post- BMI means, as well as in percent weight change, for all offenders who were obese at baseline indicated that the population lost weight (Table 2). 
However, changes in pre- and post-BMI means for women indicated that this group increased their BMIs by 1.0, whereas men decreased their BMI by 0.7. Women also had a larger increase in percent weight change; in other words, women who were obese at baseline became more obese, whereas obese men lost weight.

Table 2. Characteristics of Offender Population Classified as Obese at Baseline

\begin{tabular}{|c|c|c|c|c|c|c|}
\hline \multirow[b]{2}{*}{ Characteristic } & \multicolumn{2}{|c|}{ Female } & \multicolumn{2}{|c|}{ Male } & \multicolumn{2}{|c|}{ Total } \\
\hline & $\begin{array}{c}\text { n (\%) } \\
\text { Mean (SD) }\end{array}$ & $95 \% \mathrm{CI}$ & $\begin{array}{c}n(\%) \\
\text { Mean (SD) }\end{array}$ & $95 \% \mathrm{CI}$ & $\begin{array}{c}\text { n (\%) } \\
\text { Mean (SD) }\end{array}$ & $95 \% \mathrm{CI}$ \\
\hline $\begin{array}{l}\text { Gend } \\
\text { er }\end{array}$ & $119(12.1)$ & & 863 (87.9) & & $982(100.0)$ & \\
\hline African American & 38 (31.9) & & 327 (37.9) & & $365(37.2)$ & \\
\hline White & $80(67.2)$ & & $513(59.4)$ & & $593(60.4)$ & \\
\hline Age (years) & $40.37(9.5)$ & {$[38.7,42.1]$} & $40.7(10.3)$ & {$[40.0,41.4]$} & $40.6(10.2)$ & {$[40.0,41.3]$} \\
\hline $\begin{array}{l}\text { Incarceration } \\
\text { (years) }\end{array}$ & $8.0(5.9)$ & {$[6.7,9.2]$} & $10.5(7.6)$ & {$[9.9,11.1]$} & $10.5(7.4)$ & {$[9.7,10.8]$} \\
\hline Pre-BMI & 36.2 (5.3) & {$[35.2,37.2]$} & $34.2(4.4)$ & {$[33.9,34.5]$} & 34.7 (4.5) & {$[34.2,34.8]$} \\
\hline Post-BMI & $37.2(5.6)$ & {$[36.2,38.2]$} & $33.5(4.6)$ & {$[33.2,33.8]$} & 34.0 (4.9) & {$[33.6,34.3]$} \\
\hline BMI Change & $1.0(3.3)$ & {$[0.4,1.6]$} & $-0.7(3.1)$ & {$[-0.9,-0.5]$} & $-0.5(3.2)$ & {$[-0.7,-0.3]$} \\
\hline \% Weight Change & $3.1(8.9)$ & {$[1.4,4.7]$} & $-1.9(8.8)$ & {$[-2.5,-1.3]$} & $-1.3(8.9)$ & {$[-1.9,-0.7]$} \\
\hline
\end{tabular}

There were significant differences between women and men classified as obese upon entry into corrections (Table 3). Changes in BMI status were evaluated to determine whether or not there were population differences in regard to groups becoming more obese, having no changes in BMI or moving from obese to non-obese during incarceration. There were significant differences between women and men in regard to changes in their obesity status. In the total population, a greater proportion of women compared to men became obese. A larger proportion of men who were obese at baseline lost enough weight that they were no longer classified as obese at the conclusion of the analysis.
Along with changes in obesity status, this investigation sought to determine if there were gender differences for the population classified as obese in regard to gaining medically significant weight (an increase $\geq 7 \%$ of baseline weight). Women who were obese at baseline gained $7 \%$ or more weight in greater proportions than men (Table 3). Thus, women who were obese at baseline became more obese in greater proportions than men. The chi-square statistic indicated that there were significant proportion differences within the population that was obese at baseline; a greater proportion of women compared to men gained medically significant weight.

Table 3. Changes in Obesity Status and Weight: Obese and Total Study Populations

\begin{tabular}{|c|c|c|c|c|}
\hline & $\begin{array}{c}\text { Female } \\
\text { n (\%) }\end{array}$ & $\begin{array}{c}\text { Male } \\
\text { n (\%) }\end{array}$ & $\chi^{2}$ & $p$ \\
\hline \multicolumn{5}{|c|}{ Change in Obesity Status } \\
\hline Total Population & & & 8.5 & .014 \\
\hline Obese to non-obese & $6(3.7)$ & $173(7.0)$ & & \\
\hline No change & $134(81.7)$ & 2070 (84.2) & & \\
\hline Non-obese to obese & $24(14.6)$ & $215(8.8)$ & & \\
\hline Obese Population & & & 15.8 & $<.001$ \\
\hline Obese to non-obese & $6(5.0)$ & $173(20.1)$ & & \\
\hline No change & $113(95.0)$ & $690(80.0)$ & & \\
\hline \multicolumn{5}{|c|}{ Significant Weight Gain } \\
\hline Total Population & & & 29.5 & $<.001$ \\
\hline$<7 \%$ & $96(58.5)$ & $1898(77.2)$ & & \\
\hline$\geq 7 \%$ & $68(41.5)$ & $560(22.8)$ & & \\
\hline Obese Population & & & 34.0 & $<.001$ \\
\hline$<7 \%$ & $81(68.1)$ & $760(88.1)$ & & \\
\hline$\geq 7 \%$ & 38 (31.9) & 103 (11.9) & & \\
\hline
\end{tabular}


In addition to demonstrating differences in obesity status and medically significant weight gain, the Wilcoxon twosample test indicated that women and men who entered corrections classified as obese differed from each other in regard to changes in BMI $(p<0.001)$ and percent weight change ( $p<0.001)$, (Figure 2$)$. There also were significant gender differences for the population not classified as obese when they entered corrections. Women who were not obese at baseline had a $4.2 \%$ increase in BMI and $16.7 \%$ weight change during their incarceration, values that were significantly different from those for men $(p<0.001$ and $p$ $<0.001$, respectively), who had a 1.0 change in BMI and a percent weight change of $3.9 \%$. Further, there were significant differences for change in BMI $(p<0.001)$ and percent weight change ( $p<0.001)$ between women initially classified as obese and women who were not obese at baseline; women classified as obese upon entry into corrections gained less weight than their peers who were not obese at baseline. Men classified as obese at baseline had significant differences for change in BMI $(p<.001)$ and percent weight change $(p<.001)$ compared to men who were not obese when they entered corrections; men who were obese at baseline lost weight in comparison to men who were not obese when they entered corrections.

Figure 2. Changes in \% Weight for Obese and Total Populations

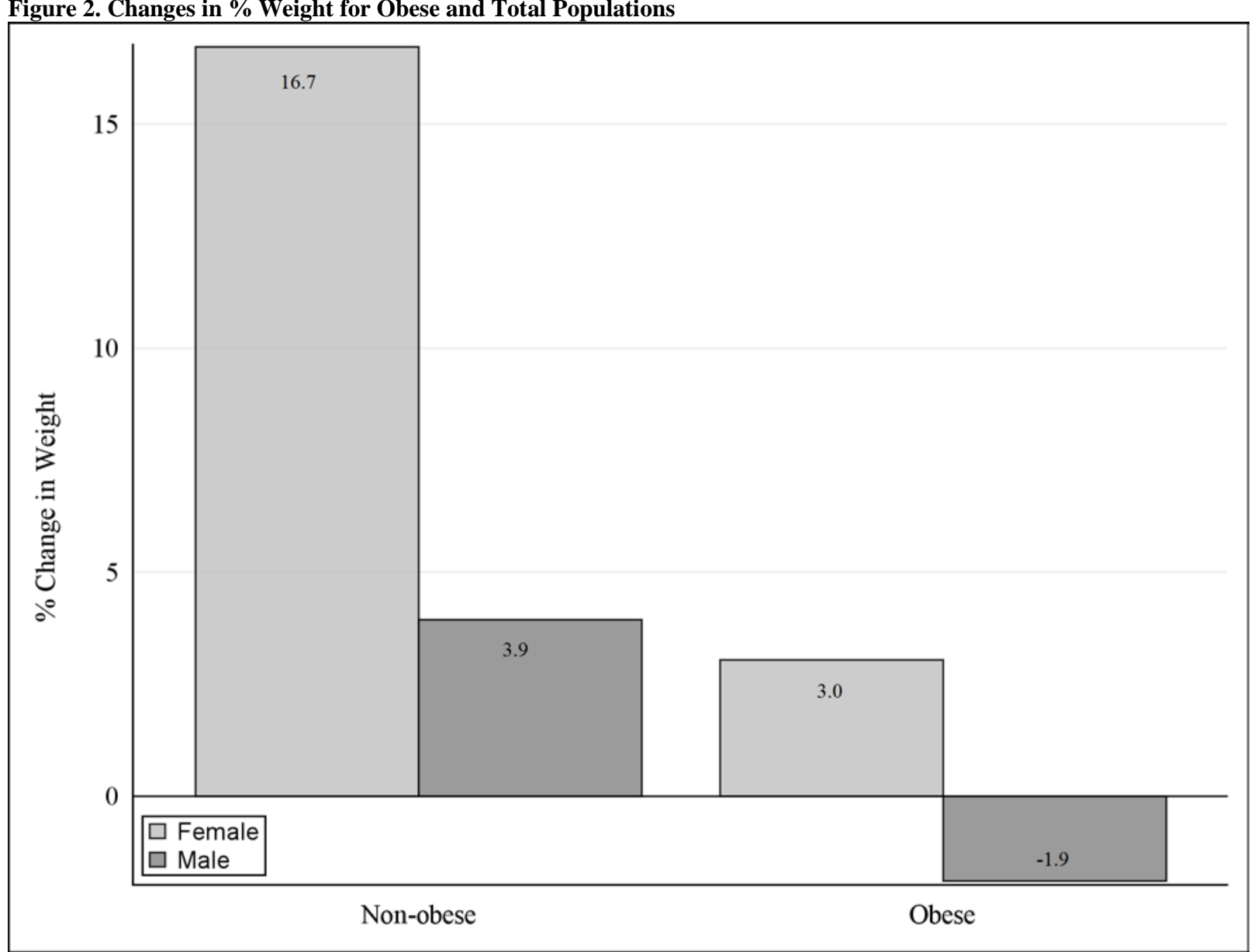

There were no significant differences for changes in BMI or percent weight change in regard to race. African Americans who were obese at baseline decreased their BMI by 0.5 and lost $1.2 \%$ of their initial weight compared to a BMI decrease of 0.5 and $1.3 \%$ loss of baseline weight for Whites. Further, there were no correlations between changes in BMI or percent weight change and age or length of incarceration in regard to gender or race for the population that entered corrections as obese or not obese. Although not reaching the $p \leq 0.05$ level, there were, for White female offenders, nearsignificant correlations between length of incarceration and change in BMI $(p=0.08)$ and percent change in weight ( $p=$ .09). White females who had been incarcerated for longer periods of time had greater weight increases relative to White females who had been in corrections for shorter durations.

\section{DISCUSSION}

The present study found that there are significant differences in changes in BMI and percent weight change in regard to gender and obesity status. Women, in comparison to men, had greater increases in BMI and percent weight change regardless of whether they entered corrections obese or not. Men who were obese at baseline lost weight. Women and men who did not enter corrections classified as obese had greater increases in BMI and percent weight change compared to the population that was already obese at baseline.

Although there are few studies comparing changes in weight between correctional populations classified as obese and not obese, the findings in regard to gender are consistent with 
other investigations that have included women offenders. Those that have investigated weight gain in corrections have found that women gain more weight than men during their incarceration (Gates \& Bradford, 2015; Herbert, Plugge, Foster, \& Doll, 2012). Further, women offenders typically have greater rates of obesity than men (Gates \& Bradford, 2015; Herbert et al., 2012; Houle, 2014; Maruschak et al., 2015).

African Americans at baseline and at the conclusion of the study had higher rates of obesity than Whites, as other reports and studies have found. The Center for Disease Control and Prevention (CDC) has reported that African Americans and Hispanics have much higher rates of obesity than Whites (Ogden, Carroll, Fryar, \& Flegal, 2015). The Bureau of Justice Statistics reported that African American offenders are more likely to be obese than Whites and Hispanics (Maruschak et al., 2015). Other correctional health studies have found that minorities, particularly African Americans, are more obese than other populations (Chan et al., 2013; Houle, 2011, 2014).

However, the present enquiry did not find that African Americans, obese or not, gained more weight than Whites. African Americans who were obese at baseline lost weight and the group that was not obese when they entered corrections had a smaller increase in BMI compared to Whites. This finding does not appear frequently among correctional health studies, which are often conducted over shorter time frames or are cross-sectional. It departs from results of other investigations that have not measured changes in BMI or percent weight change within the population classified as obese at baseline. There was no significant relationship between age or length of incarceration and obesity status (obese at baseline or not) or changes in weight. Correctional studies have not been consistent in regard to the relationship between weight gain or obesity and age or length of incarceration. For incarcerated persons, obesity rates increase with age (Maruschak et al., 2015), but there are also findings that indicate that weight gain is attenuated with longer durations (Clarke \& Waring, 2012).

The gender disparity described here provides an opportunity for corrections officials to evaluate the extent to which they are meeting the physical and mental health needs of women. Other investigators have questioned the capacity of correctional facilities to meet the health needs of women, but these concerns were not specifically related to weight gain or obesity (Harner \& Riley, 2013; Sims, 2013; van den Bergh, Gatherer, Fraser, \& Moller, 2011). Mental health may be a factor for women gaining weight and becoming obese; this may be an area in which corrections can improve services. The most recent report from the Bureau of Justice Statistics shows that depression and psychoses are reported for $23.5 \%$ and $15.4 \%$ of offenders in state DOCs; about $15 \%$ of these offenders are prescribed antidepressant or antipsychotic medications (Glaze \& James, 2006). Women offenders are overrepresented among the population seeking mental health services and taking psychotropic medications (Hassan et al., 2014). Further, antidepressant and antipsychotic medications have been found to contribute to weight gain and obesity (Bak et al., 2014; Berkowitz \& Fabricatore, 2011; Grundy, Cotterchio, Kirsh, \& Kreiger, 2014; Shams \& Muller, 2014; Wang, Wu, \& Ching, 2014).

In addition to apparent gaps or inadequacies in meeting the physical and mental health needs of women, particularly those related to obesity and risk for comorbid conditions, corrections has a structural and historical challenge to address. National data for corrections indicate that the distribution of women is much smaller than men (Maruschak et al., 2015). Thus, facilities for women typically have smaller geographical footprints than those for men. The larger population of men also may provide, in a sense, economic justification for providing expanded services. These realities suggest that women receive fewer opportunities (e.g., work releases, maintenance and landscaping jobs, and recreational activities) in comparison to men (Belknap, 1996; Cohen, 2010; Mallicoat, 2015; Meek \& Lewis, 2014). Stress is related to weight gain (Bergmann, Gyntelberg, \& Faber, 2014), and physical activity can reduce stress along with weight (Rasiah et al., 2015). However, the physical environment of correctional facilities may not be conducive for women to reduce stress through physical activity and appropriate nutrition. Even if programs exist, however, the environment may not encourage women to benefit from such programs and to improve their health. According to some, the only exercise for many incarcerated women is walking to and from meals (Clarke \& Waring 2012). Also, due to the large populations of men, DOCs typically have designed their meal plans for these populations providing a greater than necessary caloric diet for women (Herbert et al., 2012).

An understanding of the factors that contribute to weight loss among men who were obese at baseline may be instructive for creating an environment where women also decrease their weight. Some factors appropriate for men may or may not be adaptable for women. A review of services and the environment under which women reside in corrections also may inform administrators where gaps exist. Along with understanding the environment in which men and women live within corrections, much can be learned from focus groups and interviews with women in regard to barriers and obstacles they perceive in regard to losing weight.

Although DOCs are not always perceived to be a component of public health, the health of offenders affects the greater public health picture. Health disparities that exist in nonincarcerated communities become intermingled with the correctional population once individuals are incarcerated. Modifiable health risks, such as obesity, have an impact on the communities from which offenders come and to which they will eventually return. For example, in this correctional population, women and men on average were eligible for parole in 10.0 years $(7.4), 95 \%$ CI $[8.6,11.3]$ and 13.9 years (11.1), 95\% CI [13.4, 14.5], respectively. Health services can vary widely across correctional jurisdictions and resources are often limited. However, incarceration provides an opportunity for implementation of public health 
interventions focused on improving health outcomes for women and men offenders. As a vulnerable population, offenders represent a group with numerous health disparities and risks upon entry into corrections (Bai, Befus, Mukherjee, Lowy, \& Larson, 2015; Ginn, 2012; Herbert et al., 2012).

These results show that women compared to men often enter the system with obesity problems and while incarcerated continue to gain weight. The correctional environment provides an opportunity to concentrate on modifiable risk factors, such as diet and physical activity through education and development of programs to decrease sedentary living styles. With obesity in epidemic proportions in the United States and correctional facilities filled to capacity, it is in the best interest of society and DOCs to adapt relevant policies and provide sufficient resources for better health outcomes for this population.

Although this study was limited in scope, there were several variables that may explain the gender disparity. Offenders who were on special diets (e.g., low sodium, restricted caloric, and renal meals) ordered by their primary care providers were not included. Information in regard to records of commissaries, the correctional equivalent to markets, where offenders use credit to make purchases of food and other items was not collected. Special diets and commissary records were outside the electronic health records and offender management systems.

In future research, use of psychotropic medications and their association with weight gain and obesity may be explored; however, the present study did not collect the population's complete medication history so that adherence could be assessed. Weight loss or physical activity programs provided by the DOC and the physical design of the facilities (i.e., opportunities for physical activities) were not evaluated. Information about programs and physical space would have provided additional context to understand the environment in which women and men live and may have been, in part, explanatory for gender differences.

This study also was limited to investigation of gender disparities in regard to changes in BMI, weight, and obesity status using bivariate analysis. Differences in length of incarceration, pre-BMI classification, and the ratio between African Americans and Whites were observed. Future efforts should include multivariate analyses to understand the effects of demographics, baseline obesity classifications, and pre-existing conditions between genders and changes in obesity status, weight, and BMI; appropriate multicollinearity examinations will also help explain these effects (Yoo et al., 2014). Non-parametric data-mining methods are an effective approach to identifying factors associated with gender disparities (Yoo, Ference, Cote, \& Schwartz, 2012).

\section{CONCLUSION}

There are relatively few published studies of incarcerated populations with regard to weight gain (Clarke \& Waring, 2012). As determined in the current effort, women gained more weight and became more obese during incarceration, but men in the same environment lost weight. Factors related to weight gain among incarcerated populations are complex and multifaceted (Ginn, 2012). Future investigators should focus on women's access to physical activity, appropriate caloric intake and nutritional choices, and their use of pharmaceuticals. Educational opportunities to understand the importance of physical activity and proper nutrition should be provided.

According to the CDC's report on obesity in the United States, people make choices regarding physical activity and nutrition based on their community and environment (Adult Obesity Causes \& Consequences, 2015). If indeed correctional facilities are generally designed for men, future investigations are needed to address the gaps in services for women.

\section{Acknowledgements}

The Institute of Public and Preventive Health, Augusta University supported this study.

\section{References}

Adult Obesity Causes \& Consequences. (2015). Atlanta, GA: Centers for Disease Control and Prevention. Retrieved from http://www.cdc.gov/obesity/adult/causes.html.

Arterburn, D., Wood, G. C., Theis, M. K., Westbrook, E. O., Anau, J., Rukstalis, M., . . . Gerhard, G. S. (2015). Antipsychotic medications and extreme weight gain in two health systems. Obes Res Clin Pract.

Bai, J. R., Befus, M., Mukherjee, D. V., Lowy, F. D., \& Larson, E. L. (2015). Prevalence and predictors of chronic health conditions of inmates newly admitted to maximum security prisons. J Correct Health Care, 21(3), 255-264.

Bak, M., Fransen, A., Janssen, J., van Os, J., \& Drukker, M. (2014). Almost all antipsychotics result in weight gain: a metaanalysis. PLoS One, 9(4), e94112.

Belknap, J. (1996). Access to programs and health care for incarcerated women. Federal Probation, 60(4), 34.

Bergmann, N., Gyntelberg, F., \& Faber, J. (2014). The appraisal of chronic stress and the development of the metabolic syndrome: a systematic review of prospective cohort studies. Endocr Connect, 3(2), R55-80.

Berkowitz, R. I., \& Fabricatore, A. N. (2011). Obesity, psychiatric status, and psychiatric medications. Psychiatr Clin North Am, 34(4), 747-764.

BRFSS Prevalence \& Trends Data [online]. (2015). Atlanta, GA: Centers for Disease Control and Prevention, National Center for Chronic Disease Prevention and Health Promotion, Division of Population Health. Retrieved from http://www.cdc.gov/brfss/brfssprevalence/.

Chan, L. F., Zai, C., Monda, M., Potkin, S., Kennedy, J. L., Remington, G., .. . De Luca, V. (2013). Role of ethnicity in antipsychotic-induced weight gain and tardive dyskinesia: genes or environment? Pharmacogenomics, 14(11), 1273-1281.

Clarke, J. G., \& Waring, M. E. (2012). Overweight, obesity, and weight change among incarcerated women. J Correct Health Care, 18(4), 285-292.

Cohen, M. L. (2010). Editorial. International Journal of Community Music, 3(1), 3-6.Curtis, J., Watkins, A., Rosenbaum, S., Teasdale, S., Kalucy, M., Samaras, K., \& Ward, P. B. (2015). Evaluating an individualized lifestyle and life skills intervention to prevent antipsychotic-induced weight gain in first-episode psychosis. Early Interv Psychiatry.

Gates, M. L., \& Bradford, R. K. (2015). The impact of incarceration on obesity: are prisoners with chronic diseases becoming overweight and obese during their confinement? $J$ Obes, 2015, 532468. 
Ginn, S. (2012). Prison environment and health. BMJ, 345, e5921.

Glaze, L., \& James, D. (2006). Mental health problems of prison and jail inmates. Bureau of Justice Statistics. Retrieved from http://www.bjs.gov/index.cfm?ty=pbdetail\&iid=789

Grundy, A., Cotterchio, M., Kirsh, V. A., \& Kreiger, N. (2014). Associations between anxiety, depression, antidepressant medication, obesity and weight gain among Canadian women. PLoS One, 9(6), e99780.

Harner, H. M., \& Riley, S. (2013). The impact of incarceration on women's mental health: responses from women in a maximumsecurity prison. Qual Health Res, 23(1), 26-42.

Hassan, L., Frisher, M., Senior, J., Tully, M., Webb, R., While, D., \& Shaw, J. (2014). Health services and delivery research: A cross-sectional prevalence survey of psychotropic medication prescribing patterns in prisons in England. Southampton (UK): NIHR Journals Library.

Herbert, K., Plugge, E., Foster, C., \& Doll, H. (2012). Prevalence of risk factors for non-communicable diseases in prison populations worldwide: a systematic review. Lancet, 379(9830), 1975-1982.

Houle, B. (2011). Obesity disparities among disadvantaged men: national adult male inmate prevalence pooled with nonincarcerated estimates, United States, 2002-2004. Soc Sci Med, 72(10), 1667-1673.

Houle, B. (2014). The Effect of incarceration on adult male bmi trajectories, United States, 1981-2006. J Racial Ethn Health Disparities, 1(1), 21-28.

Mallicoat, S. L. (2015). Women and crime : a text/reader (2nd edition. ed.). Thousand Oaks, CA: SAGE.

Maruschak, L. M., Berzofsky, M., \& Unangst, J. (2015). Medical problems of state and federal prisoners and jail inmates, 201112. Bureau of Justice Statistics. Retrieved from http://www.bjs.gov/index.cfm?ty=pbdetail\&iid=5219

Meek, R., \& Lewis, G. E. (2014). Promoting well-being and desistance through sport and physical activity: the opportunities and barriers experienced by women in english prisons. Women \& Criminal Justice, 24(2), 151.
Ogden, C. L., Carroll, M. D., Fryar, C. D., \& Flegal, K. M. (2015). Prevalence of obesity among adults and youth: United States, 2011-2014. NCHS Data Brief(219), 1-8.

Rasiah, R., Thangiah, G., Yusoff, K., Manikam, R., Chandrasekaran, S. K., Mustafa, R., \& Bakar, N. B. (2015). The impact of physical activity on cumulative cardiovascular disease risk factors among Malaysian adults. BMC Public Health, 15, 1242.

Shams, T. A., \& Muller, D. J. (2014). Antipsychotic induced weight gain: genetics, epigenetics, and biomarkers reviewed. Curr Psychiatry Rep, 16(10), 473.

Sims, J. (2013). Is mental heal care in women's prisons adequate? Nurs Times, 109(46), 12-15.

Tek, C., Kucukgoncu, S., Guloksuz, S., Woods, S. W., Srihari, V. H., \& Annamalai, A. (2015). Antipsychotic-induced weight gain in first-episode psychosis patients: a meta-analysis of differential effects of antipsychotic medications. Early Interv Psychiatry.

van den Bergh, B. J., Gatherer, A., Fraser, A., \& Moller, L. (2011). Imprisonment and women's health: concerns about gender sensitivity, human rights and public health. Bull World Health Organ, 89(9), 689-694.

Wang, P. S., Wu, S. L., \& Ching, H. Y. (2014). The use of psychiatric drugs and worsening body mass index among inpatients with schizophrenia. Int Clin Psychopharmacol, 29(4), 235-238.

World Health Organization. (2004). Appropriate body-mass index for Asian populations and its implications for policy and intervention strategies. The Lancet, 363(9403), 157-163.

Yoo, W., Ference, B. A., Cote, M. L., \& Schwartz, A. (2012). A comparison of logistic regression, logic regression, classification tree, and random forests to identify effective gene-gene and gene-environmental interactions. Int J Appl Sci Technol, 2(7), 268.

Yoo, W., Mayberry, R., Bae, S., Singh, K., Peter He, Q., \& Lillard, J. W., Jr. (2014). A study of effects of multicollinearity in the multivariable analysis. Int J Appl Sci Technol, 4(5), 9-19. 